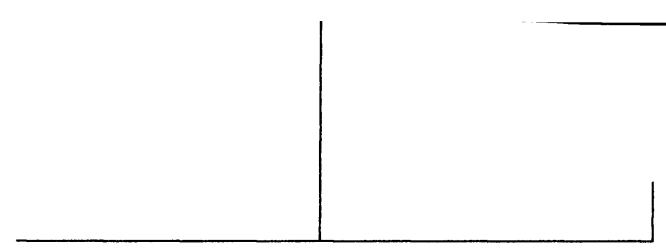

Rev. Latinoam. Psicopat. Fund., IX, 2, 293-299

\title{
Medicina em mudança: notícias recentes
}

\author{
Mônica Teixeira
}

A indústria da medicina passa por uma transição nos países centrais - onde se concentra e vive seu estágio mais avançado. Os ventos da mudança já afetaram o modo de produção de medicamentos. Os custos dos serviços médicos pressionam a organização dos sistemas de saúde. $O$ aparato jurídico de proteção à propriedade intelectual, concebido para estimular a inovação e a descoberta, apresenta-se atualmente como um entrave ao desenvolvimento de novas tecnologias - que, diz a voz do século, fará nossas vidas melhores e mais longas. Mas na pesquisa em medicina, ponto de partida das esperadas tecnologias, casos de fraude se sucedem; pacientes questionam o direito dos cientistas de usarem o que extraem do corpo deles; e todos os participantes de um ensaio clínico que receberam certa droga experimental adoeceram gravemente. "Observando a Medicina", nesta edição, reúne histórias que falam dessas mudanças.

Valores

De acordo com a US Agency for Healthcare Research and Quality, o gasto com o tratamento do que é chamado de "trauma" - acidentes dos mais variados tipos - chegou a US\$ 71,6 bilhões por ano. Mais do que o investido no tratamento de doenças cardíacas e suas consequiências 


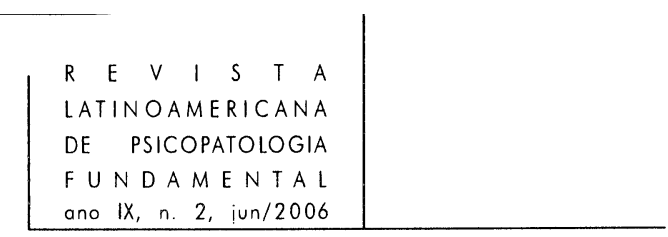

- US\$ 67,8 bilhões -, e quase o dobro dos US $\$ 48,4$ bilhões despendidos com os muitos cânceres que afligem a humanidade. A revista Lancet, ao comentar a informação, observa que não há aumento do número ou dos tipos de acidentes. É o custo da "nova tecnologia médica para salvar vidas". Mas o trauma permanece a quinta maior causa de morte nos EUA, para o conjunto da população, e a primeira para os que têm menos de 35 anos. O orçamento do Ministério da Saúde no Brasil, para 2006, deverá ser de $\mathrm{R} \$ 4,7$ bilhões. Usando dólares PPP - que levam em conta o poder de compra de cada país e, por isso, considerados mais apropriados para a comparação -, equivalem a US $\$ 5$ bilhões: o gasto público com saúde no Brasil representa cerca de $8 \%$ do dispêndio com acidentes nos EUA.

\section{Movimento da Big Pharma, tipo I}

As grandes companhias farmacêuticas têm poucas drogas novas e promissoras para entrar em linha de produção. Por outro lado, as patentes dos medicamentos líderes em vendas estão expirando. Um líder em vendas é, por exemplo, o Zocor, da Merck, para baixar níveis de colesterol: em 2005, vendeu US\$ 4,5 bilhões nos EUA (quase tanto quanto o orçamento do Ministério da Saúde). Em junho de 2006, um genérico do Zocor entrará no mercado norteamericano - as vendas vão diminuir, por causa da concorrência, e o preço vai baixar. Em novembro de 2005, a Merck anunciou que, até 2008, vai fechar cinco de suas 31 fábricas e demitir 7 mil funcionários dos 62 mil que emprega no mundo. A empresa, a terceira maior dos EUA, enfrenta nos tribunais dezenas de ações em que é acusada de comercializar o antiinflamatório Vioxx, apesar de saber da possibilidade de o medicamento causar problemas cardíacos em uma parte (pequena) daqueles que se utilizaram dele. A Pfizer, a maior farmacêutica do mundo em faturamento (US $\$ 52$ bilhões em 2004, US\$ 16 bilhões de lucro), anunciou o mesmo tipo de enxugamento em abril de 2005 - seus diretores prometeram a investidores cortar $12 \%$ dos custos, ao mesmo tempo em que anunciaram que as vendas daquele ano não cresceriam em relação a 2004. Um dos problemas enfrentados pela Pfizer - mas não o maior - é a queda de vendas do Viagra. Segundo The New York Times, os médicos prescreveram 10\% menos Viagra e similares em outubro de 2005, em relação a outubro de 2004. Até 2007 , informa a companhia, expiram patentes de produtos dela que agora respondem por $30 \%$ do faturamento. 


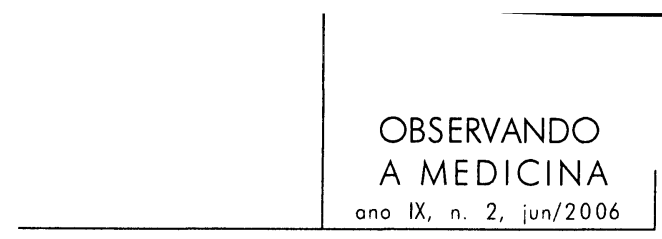

Movimento da Big Pharma, tipo II

No dia 6 de abril de 2006, a mesma Pfizer anunciou a aquisição de uma empresa de biotecnologia chamada Rinat Neuroscience. O patrimônio da Rinat se constitui de uma droga em início de pesquisa para doença de Alzheimer, e outra para a dor causada por osteoartrite já em fase II de ensaios clínicos - aquela em que se verifica a toxicidade de uma droga em grupos grandes de voluntários. A empresa afirmava ter mais dois produtos em fase de pesquisa, um deles para enxaqueca. Todos os produtos se baseiam em proteínas engenheiradas. Embora os valores não tenham sido divulgados, a imprensa supôs que a Pfizer pagou centenas de milhares de dólares. Esta foi a quarta companhia de biotecnologia que buscam drogas a partir do entendimento das doenças em nível molecular comprada pela Pfizer. O porta-voz do negócio foi o diretor global de pesquisa e desenvolvimento da Pfizer. Por quê? Porque a compra da Rinat, e das outras, sinaliza a tendência mais atual de organização do drug development - uma espécie de terceirização da pesquisa, e dos riscos envolvidos.

A forma tradicional de busca de novas drogas, mais comumente usada pelas companhias farmacêuticas, testa milhares de compostos contra alvos in vitro (relacionados a doenças), para selecionar aqueles que poderão dar origem a um medicamento, muitas anos e muito dinheiro depois. No modo de produção das empresas de biotecnologia, os custos também são altos. Mas elas são enxutas, muito focadas em pesquisa e desenvolvimento (ao contrário das companhias farmacêuticas que, além de inventarem drogas, também as comercializam. A Pfizer, por exemplo, emprega 38 mil representantes), muitas vezes em uma só linha de pesquisa. Poucas delas já colocaram medicamentos no mercado. Há alguns anos, as grandes companhias passaram a buscar essas pequenas promissoras para comprar - ou a própria companhia, como fez a Pfizer com a Rinat, ou produtos escolhidos delas. Com isso, buscam remédio para a falta de produtos novos em seus próprios pipelines, "terceirizam" a pesquisa em estruturas mais flexíveis que as deles, e - importante - diminuem o risco do início do processo, o maior do caminho que leva uma molécula a se tornar um medicamento.

\section{Movimento da Big Pharma, tipo III}

As grandes farmacêuticas estão se desfazendo de medicamentos que vendem pouco. O repórter Alex Berenson contou, no New York Times de 12 de março de 2006, que a Merck decidiu vender dois de seus medicamentos usados por pessoas com câncer - que, juntos, rendiam cerca de US\$1 milhão por ano 


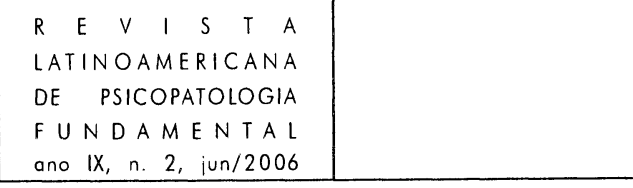

em faturamento, e são usadas por cerca de 5 mil doentes. Quem ficou dono da droga foi um outro laboratório, muito menor que a Merck, chamado Ovation Pharmaceuticals - segundo o jornal, especializado em comprar das grandes esses produtos que vendem pouco. Um desses medicamentos, de nome comercial Mustargen, existe há sessenta anos. O jornalista localizou Joyce Elkins, de 64 anos, que compra o medicamento antes fabricado pela Merck de $15 \mathrm{em} 15$ dias, para um tratamento de seis meses. No dia 3 de fevereiro de 2006, afirma o jornal, Joyce pagou US $\$ 77,50$ pela dose para 15 dias. No dia 17 de fevereiro, o preço da mesma dose havia subido para US\$ 548,01.

Por quê? Porque o novo dono do direito de fabricar e vender o Mustargen - que é usado como ungüento para tratar um tipo incomum de linfoma cutâneo -, a Ovation Pharmaceuticals, está "investindo nas instalações" para a produção do medicamento. Um detalhe: até o momento da publicação da reportagem, quem estava fabricando a droga não era a Ovation. Não: era a Merck. "É uma infelicidade que um ajuste de preços deva ocorrer", disse o diretor da Ovation ouvido pelo jornal, "mas não se investe nesse produto há anos".

Segundo a análise feita pelo repórter, com base em observadores dos usos e costumes da indústria farmacêutica, o caso ilustra a distância que há entre os preços praticados pelas empresas e o custo de produção dos medicamentos. $\mathrm{O}$ Mustargen poderia ser fabricado por qualquer companhia, uma vez que a patente expirou há muito. No entanto, por ser utilizado por poucos pacientes, não há empresas interessadas. A situação de monopólio - e mais a delicadeza da doença em questão - dá à Ovation a possibilidade de cobrar quanto quiser.

A Merck, por sua vez, informa (numa espécie de gesto de boa vontade para com os doentes) que continuará fabricando Mustargen pelo tempo que for necessário, enquanto a Ovation se organiza. Sem mais ônus perante a opinião pública. A mesma Ovation comprou, em 2003, um medicamento para a rara porfiaria, dos laboratórios Abbott. No processo, subiu o preço da dose de US\$230 para US\$ 1,9 mil.

\section{Outra vez, os valores}

A maior das empresas de biotecnologia dos EUA é a Genentech, que vendeu a maioria de seu capital à Roche, a farmacêutica suíça. A Genentech vai muito bem, ao contrário das big pharma tradicionais: no primeiro trimestre de 2006, seu lucro cresceu $48 \%$. As vendas cresceram $36 \%$, para US $\$ 1,9$ bilhões. De onde vem o bom resultado? Dos dois medicamentos contra o câncer desenvolvidos pela empresa - Avastin, para câncer do cólon, e Herceptin, para câncer de mama. O primeiro, no trimestre, vendeu sozinho US\$ 400 milhões. 


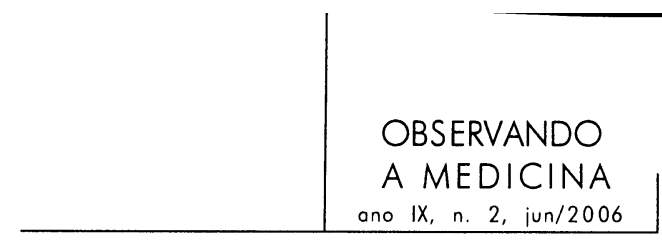

Pela dose necessária para o tratamento do câncer de cólon, a Genentech cobra US\$ 50 mil dólares, por um ano. O tratamento com Herceptin chega a US\$ 40 mil. Para sorte dos investidores, a droga também tem efeitos positivos para quem tem câncer de pulmão e de mama. Mas a quantidade necessária dobra. O preço então será de US\$100 mil para um ano de tratamento. Dr. Susan DesmondHellmann, a presidente de desenvolvimento de produto da empresa, explicou ao New York Times como foi determinado o preço do Avastin: baseado no "valor da inovação, e no valor de ser uma nova terapia". Ela não mencionou o custo de produção da droga. Analistas de mercado, segundo o jornal, estimam que, em 2009, as vendas de Avastin chegarão a US\$ 7 bilhões.

Nos EUA, esses valores recaem sobre o sistema de saúde - sobre empregadores, seguradoras, e sobre os governos federal e estaduais. Mesmo assim, cabe aos pacientes segurados pagar parte dos custos. Com preços tão altos, a contrapartida também cresce, e há norte-americanos que não suportam o ônus.

Então: no tratamento do câncer, as drogas muito bem estabelecidas e antigas, como o Mustargen e o Cosmegen, estão encarecendo; e as drogas novas - por serem novas, como explicou a doutora Desmond-Hellmann - já saem da fábrica com preços que oneram a todos.

\section{O sistema imunológico resiste}

Por oferecerem recompensas tão tentadoras, há intensa pesquisa no sentido de encontrar drogas contra o câncer - também pelo fato de serem muito diferentes os cânceres entre si, mesmo aqueles que acometem um mesmo órgão, o que abre muitas possibilidades de investigação. Uma tendência muito perseguida pretende usar o sistema imunológico para tratar a doença. A companhia alemã TeGenero desenvolveu um anticorpo que poderia ativar as células de defesa do corpo para que atacassem as células tumorais - ou, segundo a revista Nature, "acalmar articulações inflamadas pela artrite reumatóide". Como sempre no caso de drogas que têm por destino tornar-se medicamentos, a molécula um anticorpo que se liga a uma das células do sistema imunológico, o CD 28, para disparar a resposta de defesa - foi experimentada em animais com o objetivo de prever a toxicidade para seres humanos. No caso, em primatas. Em março, começou a fase I do ensaio clínico - aquela em que voluntários sadios recebem a droga, justamente para o estudo das reações. Participaram oito voluntários, todos homens. A dois foi ministrado placebo, a seis o anticorpo em teste - chamado TG1412. Todos os seis ficaram muito doentes - sofreram falência múltipla de órgãos. O órgão regulador britânico - o ensaio clínico foi conduzido no Reino Unido - suspendeu imediatamente a autorização que havia dado. Não há ainda 


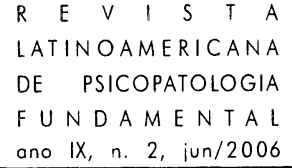

explicação para o que aconteceu. Todos os participantes ficaram bem. Quem correu o risco da fase I? Não foi uma grande farmacêutica. O anticorpo ainda poderá vir ser a base de uma droga. Se passar as fases de maior risco, a droga, ou a empresa TeGenero, poderão vir a ser compradas por uma grande farmacêutica.

Em fevereiro de 2005, a comercialização de um medicamento também baseado em anticorpos que ativam o sistema imunológico foi suspensa nos EUA. A Food and Drug Administration havia aprovado o Tysabri (natalizumab) para o tratamento da esclerose múltipla três meses antes - no sistema de aprovação acelerada da Agência. A decisão de suspender a comercialização veio quando uma paciente de 42 anos morreu de leucoencefalopatia progressiva multifocal - uma doença muito rara; outro foi diagnosticado com a doença. Dois meses depois, a reavaliação da causa de morte de um terceiro paciente levou os médicos a mais um diagnóstico de leucoencefalopatia. Todos os três participavam de um ensaio clínico de longa duração para avaliação do tratamento, obrigatório quando a droga é aprovada no fast track. A revisão prossegue para determinar se há relação entre o produto e a doença. Ninguém parece saber o que aconteceu. O FDA permitiu a retomada dos ensaios clínicos com pacientes que já estavam em tratamento.

Mas uma questão interessante foi levantada por médicos da Universidade de Stanford na revista Lancet, em março de 2006. A autópsia da mulher de 42 anos que morreu de leucoencefalopatia não revelou evidências de esclerose múltipla. $\mathrm{O}$ artigo dos dois professores observa as dificuldades para o diagnóstico preciso dessa doença - de causa desconhecida e prognóstico muito variável -, e lamenta seu engajamento no ensaio clínico: "Se o perfil de segurança de uma droga é desconhecido, engajar participantes que provavelmente teriam um prognóstico favorável e não estavam claramente em risco de desenvolver deficiências (...) expõe os pacientes a um risco desnecessário". Quer dizer: se os estudos mostrarem que a droga causou a doença, essa pessoa - que, na opinião dos professores, participou do ensaio clínico devido a critérios amplos demais para engajamento - poderia ter vivido mais, e bem.

\section{O ser humano}

Jon Sudbo, até fevereiro de 2006, era um respeitado oncologista norueguês, especializado em cânceres da boca. Em 2001, em artigo publicado na New England Journal of Medicine, comunicou a seus colegas que é possível saber o prognóstico de certas lesões da boca pela análise dos cromossomas das células encontradas nela, e tratar preventivamente aquelas que possivelmente se transformarão em lesões malignas. Em outubro de 2005, publicou na Lancet outro artigo de repercussão, com outros 12 autores (da Noruega e dos EUA). Como 


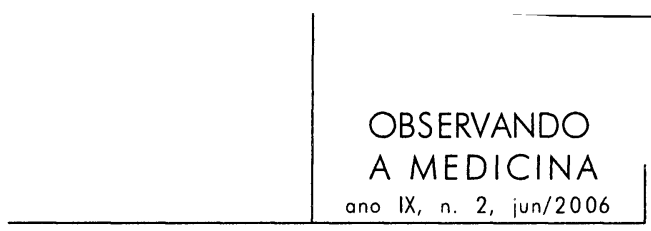

primeiro autor, Sudbo afirmava que antiinflamatórios não esteróides - aspirina, por exemplo - reduzem incidência de câncer na boca, mas aumentam o risco de morte associada a doenças cardiovasculares. A conclusão, segundo o texto, advinha da identificação e análise de 908 pessoas, das quais 454 com câncer na boca e 454 "controles". Essas pessoas foram localizadas na base de dados CONOR - sigla para Coorte da Noruega.

Sudbo descreveu a composição do grupo: gênero, idade, se fumava ou não. Em dados não publicados no artigo, relacionou também a data de nascimento de cada uma das 908 pessoas. Nenhuma das 908 pessoas existe - Sudbo inventou tudo. A 250 delas, o oncologista atribuiu a mesma data de nascimento. Todos os seus artigos estão sendo investigados, e a Lancet já retirou o de 2005. Um ensaio clínico em parte baseado nos resultados desse artigo, financiado pelo National Cancer Institute, poderá vir a ser suspenso. A fraude foi descoberta porque o acesso à base de dados em que Sudbo disse ter buscado seus 908 casos ainda não estava aberto a pesquisadores.

Sudbo admitiu a invenção, e foi demitido. Encerrou assim a sua carreira, aos 44 anos.

Tendência

A vida imortal de Henrietta Lacks - esse livro, escrito por Rebecca Skoot, chegará às livrarias dos EUA em 2007. Nele, a autora conta a história da primeira linhagem de células humanas criada em laboratório, e seu objetivo é discutir o uso que a medicina e os pesquisadores em medicina fazem de tecidos retirados de todos nós em exames clínicos. De acordo com ela, o único relatório sobre o assunto, feito pela Rand Corporation, conclui haver, em 1999, $307 \mathrm{mi}$ lhões de amostras de sangue e células diversas humanas estocadas nos Estados Unidos, retiradas de 178 milhões de pessoas. Um dos aspectos da questão é que, em muitos casos, essas amostras resultam em descobertas que enriquecem pesquisadores e laboratórios. Outro aspecto é: a quem pertencem esses tecidos? As pessoas de quem foram retirados têm direito sobre eles, e sobre o uso que será feito deles? Skoot relatou, na revista do New York Times, que pesquisas qualitativas já mostram um sentimento crescente de oposição à liberdade atual dos cientistas. Estes já se preocupam: células são uma espécie de matéria-prima da pesquisa - e se, agora, os doadores de tecidos decidem dizer: "minhas células podem ser usadas para investigar isto, mas não aquilo"? A pesquisa pode parar... e é ela, crê a cultura ocidental, que sustenta a esperança no "avanço" permanente da medicina, aquele que - supostamente - vai afastar para mais longe dos humanos a certeza da morte. 